\title{
Decay and persistence of empty bivalve shells in a temperate riverine system
}

\author{
M.I. Ilarri ${ }^{a}{ }^{*}$, A.T. Souza $^{\text {b }}$, L. Amorim ${ }^{\mathrm{c}}$, R. Sousa ${ }^{\mathrm{a}, \mathrm{c}}$

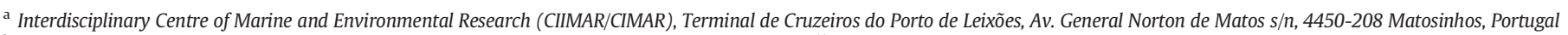 \\ b Institute of Hydrobiology, Biology Centre of the Czech Academy of Sciences, Na Sádkách 7, 37005 České Budějovice, Czech Republic \\ c CBMA - Centre of Molecular and Environmental Biology, Department of Biology, University of Minho, Campus de Gualtar, 4710-057 Braga, Portugal
}

\section{H I G H L I G H T S}

- Bivalve shells decay were evaluated.

- Decays varied among species, shell size, water flow and season.

- The thinnest shells showed the highest decays, and the thickest shells the lowest.

- An increase in shells preservation was observed when they were buried.

- Decays in lotic habitats were up to 2.13 times higher than in lentic habitats.

\section{G R A P H I C A L A B S T R A C T}

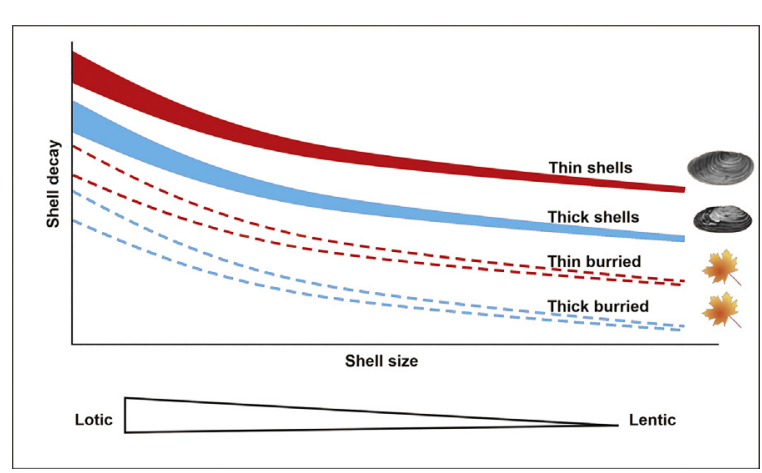

\section{A R T I C L E I N F O}

\section{Article history:}

Received 4 April 2019

Received in revised form 14 May 2019

Accepted 14 May 2019

Available online 17 May 2019

Editor: Damia Barcelo

\section{Keywords:}

Ecosystem engineer

Shell morphology

Leaf burial effect

River flow

Native species

Invasive species

\section{A B S T R A C T}

Bivalve shells can persist over a geological time, acting as important physical resources to the associated fauna. However, few studies have investigated their relevance as persistent long-term ecological attributes to the ecosystem. As such, it is relevant to investigate the shell decays in riverine systems subjected to different environmental conditions. Towards this end, shells of four bivalve species (Anodonta anatina, Corbicula fluminea, Potomida littoralis and Unio delphinus) were made available individually and in clusters of different sizes. The effects of river flow and seasonality were assessed by recording the decay rates of shells in lentic and lotic habitats throughout the year. Our results evidenced that the decays varied among species and depend on shell size, water flow and season. Thin shelled species ( A. anatina and U. delphinus) showed the highest mean percentage of decay per month, 3.17\% (lotic) and 2.77\% (lotic), respectively, and thick shelled species (C. fluminea and P. littoralis) the lowest, $2.02 \%$ (lotic) and $1.83 \%$ (lotic), respectively. Size was a relevant variable explaining decays, with the smallest shells presenting the highest values, 1.2-2.0 times higher compared to the other size classes. Also, robustness showed to be the most relevant feature explaining the decays in thick shelled species. River flow was also a relevant descriptor of the decays, with higher decays observed in the lotic compared to the lentic habitats. Furthermore, lower decays were observed mainly during summer (lentic site), and autumn (lotic site) associated to the burial effect of leaves. In summary, shells of the native species A. anatina and $U$. delphinus are expected to persist and contribute less as habitat engineering species, than shells of the native $P$. littoralis and invasive $C$. fluminea species. This is especially valid to lotic habitats where the decays were up to 2.13 times higher than in lentic habitats.

(c) 2019 Elsevier B.V. All rights reserved.

\footnotetext{
* Corresponding author.

E-mail address: martinailarri@gmail.com (M.I. Ilarri).
} 


\section{Introduction}

Organisms are capable of modifying the ecosystem in which they live, generating habitat changes through physical mechanisms (autogenic engineering) and state changes (allogenic engineering), being known as ecosystem engineers (Jones et al., 1994, 1997; Wright and Jones, 2006). The modifications generated by ecosystems engineers, including invasive species, often influence the associated fauna and flora, mainly through changes in the resources availability and/or creation or destruction of niches (Gutiérrez et al., 2014; Erwin, 2008).

A relevant faunal group of ecosystem engineers are the bivalves. These invertebrates can physically modify the ecosystems in which they live simply by the presence and persistence of their shells in the environment (Gutiérrez et al., 2003; Vaughn and Hoellein, 2018). The presence of these hard structures in the environment generates an increase in the habitat heterogeneity, which is often used by microorganisms, algae, plants and animals as substrata for attachment, refuge, reduction of the physical and/or physiological stress and transport of particles and solutes to the benthic compartment (Gutiérrez et al., 2003; Lutaenko, 2012; Lutaenko and Levenets, 2015; Novais et al., 2015, 2016; Vaughn and Hoellein, 2018). Beyond their ecological importance, bivalve shells can also persist over a geological time, acting as an ecological legacy, modulating the environment in which they occurred in a long temporal scale (Palacios et al., 2000; Wenger et al., 2019). Indeed, in a previous study, Erwin (2008) suggested that the impacts generated by ecosystem engineers have increased over time, and argued that shell beds increased since the early Phanerozoic as a reflex of shifts in the communities from a brachiopod to a molluscan dominance. Erwin (2008) also suggested that the currently predominance and persistence of these shell beds resulted in more diverse communities. In addition, Wenger et al. (2019) showed that animal remains, including shells in freshwater ecosystems which decompose slowly, may provide long-term reservoirs of several nutrients. Previous studies have also showed that bivalve shells can be used as indicator tools to monitor pollution and environmental changes, with the use of shells to detect the presence of several heavy metals in the environment (e.g. $\mathrm{Al}, \mathrm{Zn}, \mathrm{Mn}, \mathrm{Ni}, \mathrm{Co}, \mathrm{Cr}$ and others; Nuñez et al., 2012; Karbasdehi et al., 2016), and also to assess changes in water pH (Marshall et al., 2018). Therefore, it is important to understand the mechanisms behind the shell decays of different species subjected to different environmental conditions in order to better comprehend the persistence and importance of bivalve shells in the ecosystems.

Some studies highlighted the ecological importance of bivalve shells to the associated fauna (Ilarri et al., 2012; Schmidlin et al., 2012; Bódis et al., 2014; Novais et al., 2015). However, studies that have assessed their relevance as a persistent ecological attribute to the ecosystem are still scarce (but see Strayer and Malcom, 2007; Ilarri et al., 2015a). In this regard, in the present study, the shell decay rates of four bivalve species were studied to better comprehend the persistence and importance of bivalve shells in the ecosystem as a habitat-forming species, and also to understand how their persistence can vary through different environmental conditions and between distinct species.

Lentic and lotic systems can greatly differ in local habitat conditions depending on the strength of the water flow. As such, we considered to investigate the decays of bivalves shells of different species (Anodonta anatina, Corbicula fluminea, Potomida littoralis and Unio delphinus) and size when submitted to different flow conditions (lentic and lotic) all over the seasons (spring, summer, autumn and winter) in order to understand how and for how long different bivalve species contribute as ecosystem engineers under different water flow conditions. We hypothesize that: i) species with larger shells will decay slower given their lower surface area to volume ratio; ii) species with thicker and harder shells (i.e. shells of $C$. fluminea and of $P$. littoralis) will decay slower given their robustness and iii) slower decay rates will be obtained in summer months given the lower river flow in this period of the year.

\section{Material and methods}

\subsection{Study area}

The study was conducted in the Minho River (NW of the Iberian Peninsula). This river has $300 \mathrm{~km}$ of extension, originating in the province of Lugo (Spain), with its last $70 \mathrm{~km}$ serving as a geographic border between Spain (North margin) and Portugal (South margin). The Minho River drains a hydrological basin with a total area of $17,080 \mathrm{~km}^{2}$, of which 95\% is located in Spain, and 5\% in Portugal, draining NNE-SSW into the Atlantic Ocean (Sousa et al., 2005).

The study was conducted in two sites located in the international section of the Minho River (Fig. 1). Site 1 (L1) is located in the village of Cortes, Monção (Portugal), and site 2 (L2) is located in the village of Friestas, Valença (Portugal); the two sites are approximately $5.5 \mathrm{~km}$ distant. Both sites are located in shallow areas with permanent freshwater conditions and similar substratum composition (mainly of pebbles, cobbles, coarse and medium sand, macrophytes and $C$. fluminea shells). However, the water flow differs between sites, with L1 located in the main canal of the Minho River and being characterized by a fastflowing (lotic) water regime during the entire year with the exception of summer and early autumn and L2 located in a side arm of the Minho River and being characterized by a slow-flowing (lentic) water regime throughout the entire year. The classification of sites according to the water flow conditions was done qualitatively, based on previous studies performed in the study area (Sousa et al., 2007, 2008; Ilarri et al., 2015a, 2015b, 2018; Novais et al., 2017) and on empirical evidence of the water regime throughout the study period (authors personal observations).

The water of Minho River is undersaturated with $\mathrm{CaCO}_{3}\left(\mathrm{Ca}^{2}\right.$ : $9.0 \mathrm{mg} \mathrm{l}^{-1}$; mean total hardness $\mathrm{CaCO}_{3}$ : $24.4 \mathrm{mg} \mathrm{l}^{-1}$; mean pH: 7.6; for more details see Sousa et al., 2007 and Ferreira-Rodríguez et al., 2017).

\subsection{Studied shells}

For the study, intact shells of recently dead organisms of four different bivalve species, A. anatina (24 shells), C. fluminea (96 shells), $P$. littoralis (24 shells), U. delphinus (96 shells) were manually collected in the Minho River in site L1. These species were selected due to the fact that they are ecologically relevant species in the study area, and also because they present very distinct shells in terms of morphology. Anodonta anatina presents the largest, thinnest and most fragile shells in comparison with the other three species. Potomida littoralis presents the second largest shells of the selected species, however their shells are also the thickest and most robust. On the other hand, $C$. fluminea present a thick shell with ridges (well defined and concentric); however, not as much as $P$. littoralis, and is the one with the smallest shells. Unio delphinus presents a medium size shell, characterized mainly to be thin and delicate.

\subsection{Field and laboratory procedures}

Prior to the experiment all the selected shells were manually cleaned (to remove any trace of soft tissue) and weighted in a precision scale to the nearest $0.001 \mathrm{~g}$. Afterwards, shells were placed in identified (numerical code) and sealed (manual sewing) nylon net bags with $10 \mathrm{~mm}$ mesh size. Six treatments were performed, four of them consisting in one shell of each species (i.e. A. anatina, C. fluminea, $P$. littoralis and $U$. delphinus) per sealed nylon bag, and two treatments consisting in three shells of different size class (i.e. small, medium and large) per sealed nylon bag of the species $C$. fluminea and $U$. delphinus (the only species in which different size of shells were accessible in the study area). For the treatments that had size variation, the size class were defined according to the shells available in the field for each species. For $C$. fluminea the size of the shells for each class were: small (18.0-25.0 mm), medium (25.01-30.5 mm) and large 


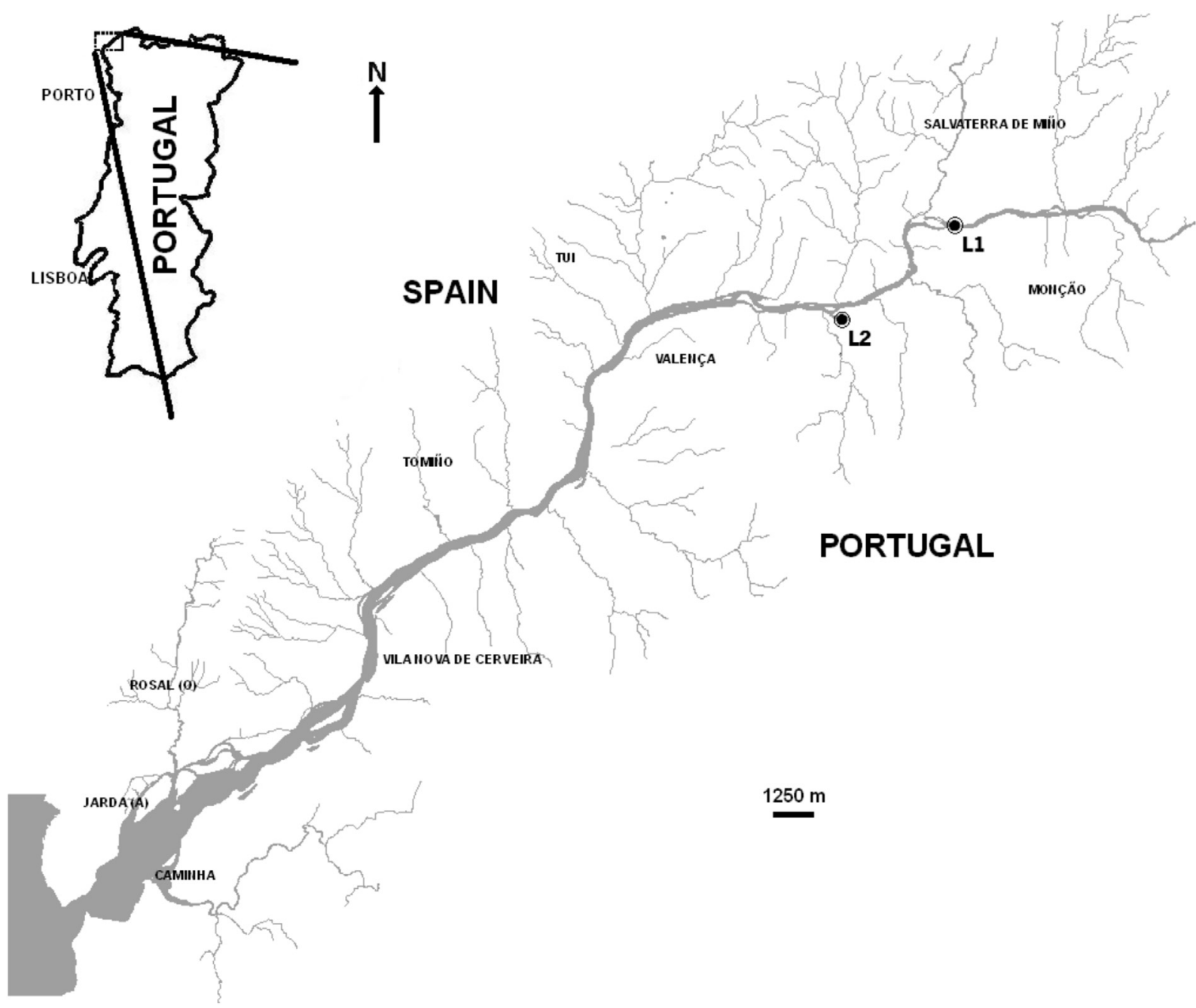

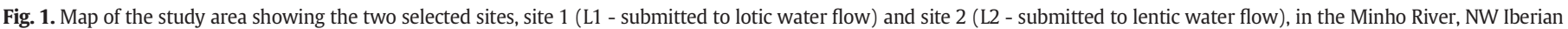
Peninsula.

(>30.5 mm), whereas for U. delphinus were: small (19.0-38.0 mm), medium (38.01-49.00 mm) and large (>49.01 mm).

Each treatment was replicated twelve times per site (i.e. L1 and L2) and season (see below) of the year. The six treatments were tied together with a string into an iron stake and placed in a fixed location at the river bottom (approximately $70 \mathrm{~cm}$ deep), near the river bank (approximately $10 \mathrm{~m}$ ).

Shells remained underwater for one month during four different periods of 2014-2015: spring (May of 2014), summer (July of 2014), autumn (November of 2014) and winter (January of 2015) to assess possible seasonal variations in the decay rates. New and intact shells were made available during each season.
After each month of experiment, shells were cleaned and dried in a gravity-convection oven at $60^{\circ} \mathrm{C}$ for 2 days and subsequently weighted. The shell decay rates were evaluated through the weight of the shells per bag in the beginning of the experiment minus the weight of the shells in the end of the experiment.

The experiment was conducted simultaneously in L1 and L2 to determine if the different water flow regimes (i.e. lotic and lentic) affected the shell decay rates all over the seasons.

Table 1

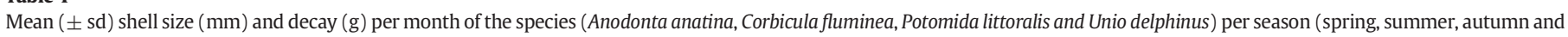
winter) and water flow (lentic and lotic).

\begin{tabular}{|c|c|c|c|c|c|c|}
\hline \multirow[t]{2}{*}{ Species } & \multirow[t]{2}{*}{ Shell size } & \multirow[t]{2}{*}{ Water regime flow } & \multicolumn{4}{|l|}{ Season } \\
\hline & & & Spring & Summer & Autumn & Winter \\
\hline \multirow{2}{*}{ Anodonta anatina } & $105.19 \pm 21.14$ & Lentic & $0.37 \pm 0.18$ & $0.29 \pm 0.13$ & $0.30 \pm 0.13$ & $0.26 \pm 0.10$ \\
\hline & $106.37 \pm 24.35$ & Lotic & $0.60 \pm 0.32$ & $0.69 \pm 0.23$ & $0.26 \pm 0.1$ & $0.56 \pm 0.16$ \\
\hline \multirow{2}{*}{ Corbicula fluminea } & $31.28 \pm 1.82$ & Lentic & $0.04 \pm 0.01$ & $0.03 \pm 0.01$ & $0.04 \pm 0.01$ & $0.05 \pm 0.01$ \\
\hline & $31.11 \pm 3.01$ & Lotic & $0.06 \pm 0.02$ & $0.09 \pm 0.02$ & $0.04 \pm 0.01$ & $0.06 \pm 0.01$ \\
\hline \multirow{2}{*}{ Potomida littoralis } & $69.41 \pm 6.05$ & Lentic & $0.17 \pm 0.03$ & $0.16 \pm 0.06$ & $0.19 \pm 0.04$ & $0.14 \pm 0.03$ \\
\hline & $71.56 \pm 9.12$ & Lotic & $0.30 \pm 0.16$ & $0.40 \pm 0.15$ & $0.18 \pm 0.05$ & $0.26 \pm 0.09$ \\
\hline \multirow{2}{*}{ Unio delphinus } & $60.48 \pm 5.72$ & Lentic & $0.1 \pm 0.03$ & $0.08 \pm 0.01$ & $0.11 \pm 0.02$ & $0.09 \pm 0.02$ \\
\hline & $60.88 \pm 5.39$ & Lotic & $0.16 \pm 0.05$ & $0.22 \pm 0.06$ & $0.08 \pm 0.02$ & $0.16 \pm 0.02$ \\
\hline
\end{tabular}




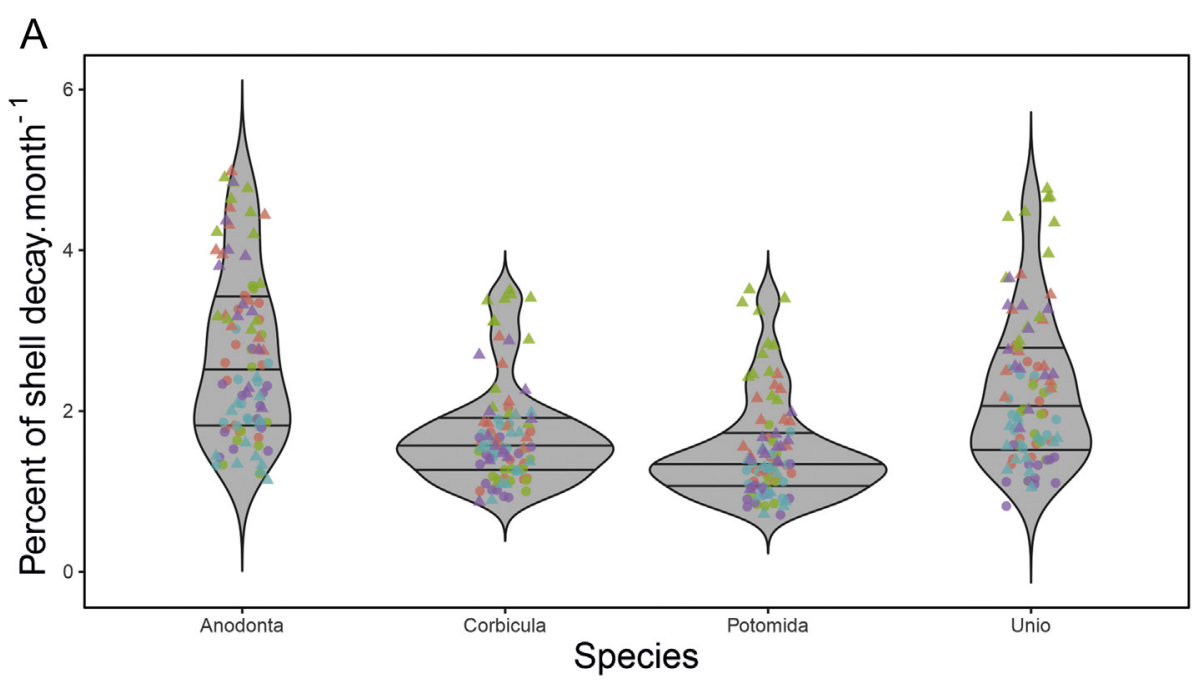

Season - spring • Summer - Autumn - Winter River flow • Lentic $\Delta$ Lotic

B

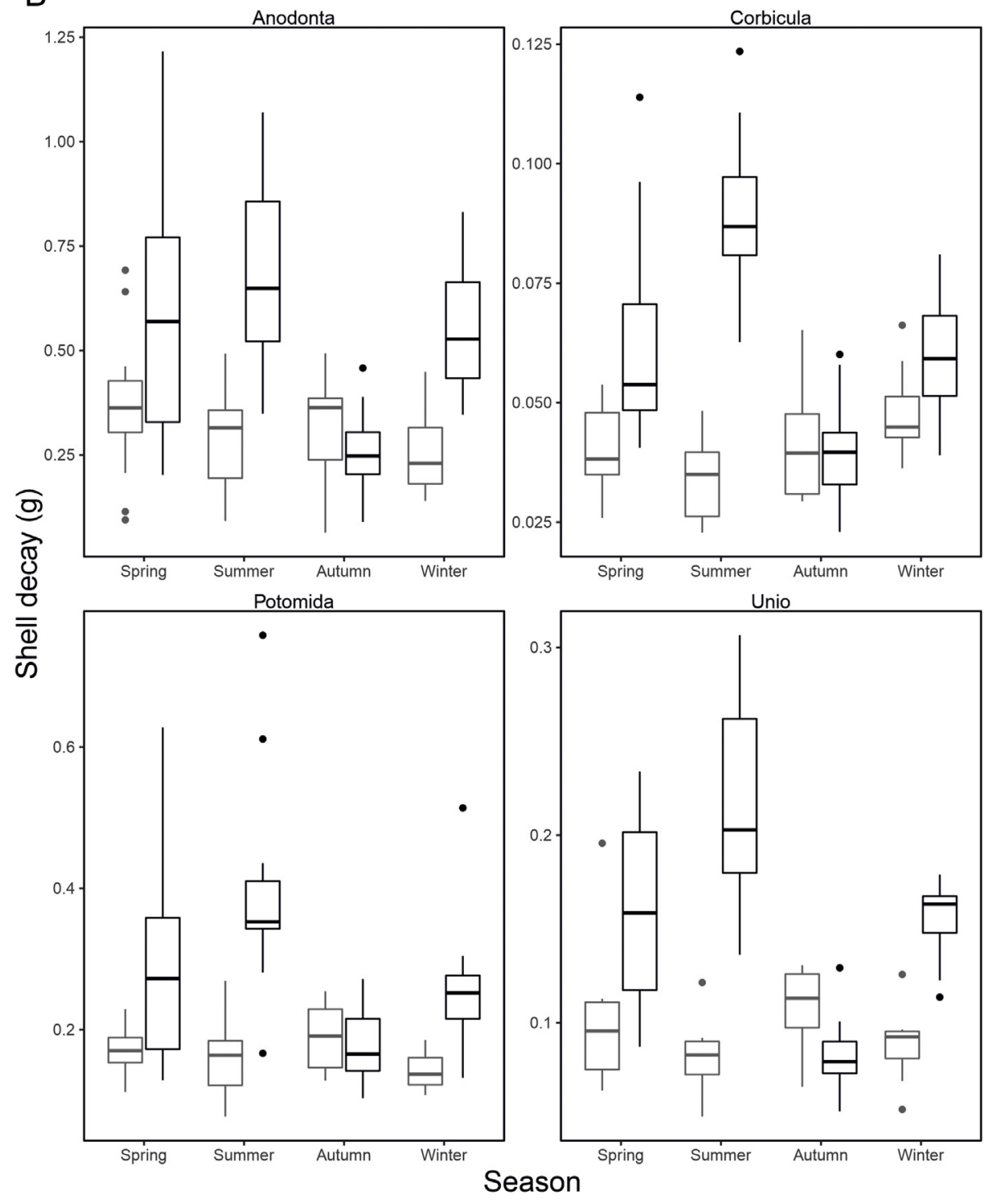

River flow 户 
Table 2

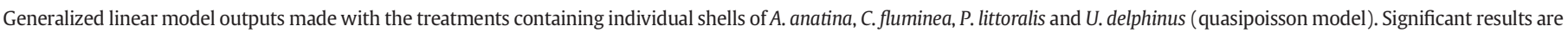
in italic.

\begin{tabular}{|c|c|c|c|c|c|}
\hline $\begin{array}{l}\text { Response } \\
\text { variable }\end{array}$ & Parameter & Estimate & SE & t-Value & P-Value \\
\hline \multirow[t]{18}{*}{ Decay } & Intercept & -2.87 & 0.11 & -25.30 & $<0.001$ \\
\hline & Size & 0.015 & 0.00093 & 17.05 & $<0.001$ \\
\hline & Species (Corbicula) & -1.91 & 0.63 & -3.063 & $<0.01$ \\
\hline & Species (Potomida) & -1.25 & 0.24 & -5.19 & $<0.001$ \\
\hline & Species (Unio) & -1.10 & 0.38 & -2.89 & $<0.01$ \\
\hline & River flow (Lotic) & -0.13 & 0.063 & -2.16 & $<0.05$ \\
\hline & Season (Spring) & 0.088 & 0.056 & 1.58 & 0.12 \\
\hline & Season (Summer) & -0.087 & 0.059 & -1.49 & 0.14 \\
\hline & Season (Winter) & -0.17 & 0.059 & -2.88 & $<0.01$ \\
\hline & Size vs species (Corbicula) & 0.04 & 0.019 & 1.86 & 0.1 \\
\hline & Size vs species (Potomida) & 0.02 & 0.0032 & 5.72 & $<0.001$ \\
\hline & Size vs species (Unio) & 0.01 & 0.0059 & 1.90 & 0.1 \\
\hline & Species (Corbicula) vs river flow (Lotic) & -0.059 & 0.11 & -0.55 & 0.58 \\
\hline & $\begin{array}{l}\text { Species (Potomida) vs river flow } \\
\text { (Lotic) }\end{array}$ & -0.082 & 0.062 & -1.31 & 0.19 \\
\hline & Species (Unio) vs river flow (Lotic) & -0.053 & 0.076 & -0.71 & 0.48 \\
\hline & River flow (Lotic) vs season (Spring) & 0.66 & 0.076 & 8.63 & $<0.001$ \\
\hline & River flow (Lotic) vs season (Summer) & 1.01 & 0.077 & 13.11 & $<0.001$ \\
\hline & River flow (Lotic) vs season (Winter) & 0.78 & 0.079 & 9.87 & $<0.001$ \\
\hline
\end{tabular}

\subsection{Data analysis}

Generalized linear models (GLMs) were performed to describe the shell decay of each selected bivalve species in different flow conditions through the seasons. As the data showed under-dispersion (i.e. the model variance was lower than the mean) the decays were modelled using the quasipoisson error distributions (following Zuur et al., 2009).

Shell decay was the response variable, size the numerical predictor variable, and river flow condition and season the predictor categorical variables. In addition, in order to account for variation in the species decays regarding size, interaction between size and species, and river flow and species, were included in the model. The interaction between river flow and season was also included in the model, given that the river flow varies through space and time. A GLM was applied for the treatments containing individual shells of each species (i.e. A. anatina, $C$. fluminea, P. littoralis and U. delphinus), and a second GLM was performed for the treatments consisting in three shells of different size of the same species (i.e. C. fluminea and U. delphinus).

The residuals of the model were visually checked regarding the assumptions of normal and homogeneous error.

The data was modelled with the glm function from the package MASS (Venables and Ripley, 2002). For the comparison of the decays regarding the different species, river flow (i.e. lentic and lotic) and season (spring, summer, autumn and winter), least-square means with a Tukey correction were made. The pairwise comparisons of least-square means were made through the lsmeans function from the package lsmeans (Lenth, 2016). All the analysis were performed using the R software ( $R$ Development Core Team, 2014).

\section{Results}

\subsection{Shells available individually}

The decays of the shells made available individually varied among species, water flow and season. Regarding the shell mass loss, A. anatina was the species with the highest values, followed by P. littoralis, $U$. delphinus and C. fluminea, respectively (Table 1 ).
The highest percentage of shell decay was also observed for $A$. anatina, followed by $U$. delphinus, $C$. fluminea and $P$. littoralis, respectively (Fig. 2a). The highest percentage of shell decays was observed for shells under lotic conditions and during summer (A. anatina $>U$. delphinus $>$ P. littoralis $>C$. fluminea); whereas for the shells submitted to lentic conditions the highest decay values were observed during spring (for A. anatina and P. littoralis) and autumn (for C. fluminea and U. delphinus) (Fig. 2a). However, it is important to note that the shells submitted to lotic conditions had a different pattern during autumn, for all the four species, with the highest decays observed in the lentic instead of the lotic condition (Fig. 2b).

The GLM showed that the interaction effects of size vs species and river flow vs season were significant (Table 2 ). The pairwise comparisons of size vs species interaction showed that the decays of $U$. delphinus were different compared to A. anatina (z.ratio, $p$-value; 5.54, $p<0.001$ ) and $P$. littoralis $(5.09, \mathrm{p}<0.001)$. Regarding the river flow vs season interaction, the pairwise test indicated that the decays had a higher variation through the seasons, compared to the lentic conditions, with the decays during autumn in the lotic conditions showing a different pattern compared to the other seasons (winter: $-11.61, p<0.001$; spring: $-14.30, \mathrm{p}<0.001$; summer: $-18.39, \mathrm{p}<0.001$ ). Spring was also different from summer $(-4.38, p<0.001)$ and winter $(3.09, p<0.05)$, and summer was different from winter $(7.57, p<0.001)$. In lentic conditions the decays were much more even through the seasons, with differences been observed only between winter and spring $(4.38, p<0.01)$. The GLM showed a high predictive capacity $\left(r^{2}=0.90\right)$.

\subsection{Shells available together}

The decays of the treatments containing shells of different sizes varied according to the species, size, water flow and season (Table 3). Unio delphinus had higher percentage of decay compared to $C$. fluminea (Fig. 3a). Overall, the smallest shells had the highest mass loss followed by the medium and large shells (Table 3 ). The highest decays were observed for the shells submitted to lotic conditions (U. delphinus $>C$. fluminea) (Fig. 3b), the only exception to this was during autumn for

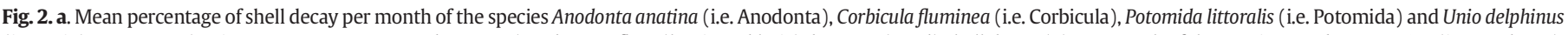

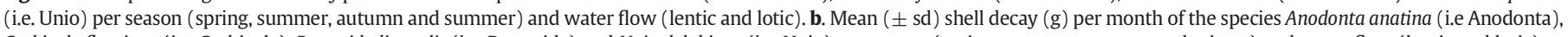
Corbicula fluminea (i.e. Corbicula), Potomida littoralis (i.e. Potomida) and Unio delphinus (i.e. Unio) per season (spring, summer, autumn and winter) and water flow (lentic and lotic). 
b- Table 3

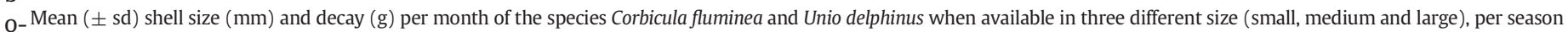
th (spring, summer, autumn and winter) and water flow (lentic and lotic).

\begin{tabular}{|c|c|c|c|c|c|c|c|}
\hline \multirow[t]{2}{*}{ - Species } & \multirow[t]{2}{*}{ Size } & \multirow[t]{2}{*}{ Shell size } & \multirow[t]{2}{*}{ Water regime flow } & \multicolumn{4}{|l|}{ Season } \\
\hline & & & & Spring & Summer & Autumn & Winter \\
\hline & Small & $21.57 \pm 1.57$ & Lentic & $0.02 \pm 0.00$ & $0.01 \pm 0.00$ & $0.01 \pm 0.00$ & $0.02 \pm 0.00$ \\
\hline \multirow[t]{2}{*}{ Corbicula fluminea } & Medium & $28.07 \pm 1.49$ & Lentic & $0.02 \pm 0.01$ & $0.01 \pm 0.00$ & $0.02 \pm 0.01$ & $0.02 \pm 0.00$ \\
\hline & Large & $36.79 \pm 2.47$ & Lentic & $0.03 \pm 0.01$ & $0.03 \pm 0.01$ & $0.04 \pm 0.00$ & $0.04 \pm 0.00$ \\
\hline \multirow[t]{3}{*}{ Corbicula fluminea } & Small & $21.89 \pm 1.90$ & Lotic & $0.03 \pm 0.01$ & $0.02 \pm 0.01$ & $0.01 \pm 0.00$ & $0.03 \pm 0.01$ \\
\hline & Medium & $28.42 \pm 4.36$ & Lotic & $0.03 \pm 0.01$ & $0.04 \pm 0.02$ & $0.02 \pm 0.00$ & $0.03 \pm 0.01$ \\
\hline & Large & $37.73 \pm 2.20$ & Lotic & $0.05 \pm 0.01$ & $0.09 \pm 0.04$ & $0.03 \pm 0.01$ & $0.06 \pm 0.02$ \\
\hline \multirow[t]{3}{*}{ Unio delphinus } & Small & $30.39 \pm 3.77$ & Lentic & $0.02 \pm 0.01$ & $0.01 \pm 0.01$ & $0.02 \pm 0.01$ & $0.01 \pm 0.00$ \\
\hline & Medium & $45.38 \pm 2.55$ & Lentic & $0.03 \pm 0.01$ & $0.03 \pm 0.01$ & $0.03 \pm 0.01$ & $0.03 \pm 0.00$ \\
\hline & Large & $65.99 \pm 4.25$ & Lentic & $0.08 \pm 0.01$ & $0.08 \pm 0.01$ & $0.09 \pm 0.02$ & $0.07 \pm 0.02$ \\
\hline \multirow[t]{3}{*}{ Unio delphinus } & Small & $31.44 \pm 5.00$ & Lotic & $0.02 \pm 0.01$ & $0.04 \pm 0.01$ & $0.01 \pm 0.00$ & $0.02 \pm 0.00$ \\
\hline & Medium & $44.09 \pm 9.06$ & Lotic & $0.06 \pm 0.02$ & $0.08 \pm 0.02$ & $0.03 \pm 0.01$ & $0.05 \pm 0.02$ \\
\hline & Large & $64.59 \pm 10.63$ & Lotic & $0.14 \pm 0.04$ & $0.23 \pm 0.05$ & $0.07 \pm 0.01$ & $0.11 \pm 0.03$ \\
\hline
\end{tabular}

which the highest values were observed for the lentic conditions (Fig. 3b).

The GLM showed that the interaction of size vs species, river flow vs species and river flow vs season were significant (Table 4). The pairwise comparisons of size vs species interaction showed that the decays of $C$. fluminea was different from U. delphinus (z.ratio, $p$-value; 10.80, $p<$ 0.001 ). Also, the river flow vs species pairwise comparisons highlighted that $C$. fluminea had a different decay in lotic when compared to the lentic conditions $(-7.98, \mathrm{p}<0.001)$; the same was observed for $U$. delphinus $(-14.00, \mathrm{p}<0.001)$. Regarding the river flow vs season interaction the pairwise comparisons indicated also a greater variation through the seasons during the lotic when compared to the lentic conditions, with the decays during autumn showing a different pattern compared to the other seasons (winter: $-4.62, \mathrm{p}<0.001$; spring: $-7.41, \mathrm{p}<0.001$; summer: $-15.37, p<0.001)$. In addition, the decays during spring were different from summer $(-9.25, \mathrm{p}<0.001)$ and winter $(3.20, p<0.05)$, and summer was different from winter $(12.54, \mathrm{p}<0.001)$. In lentic conditions the pairwise comparisons indicated that the decays were only different between autumn and summer $(3.74, p<0.01)$. The GLM showed a high predictive capacity $\left(r^{2}=0.87\right)$.

\section{Discussion}

Bivalves can be important ecosystem engineers, since among other features, they provide large amounts of shells (Gutiérrez et al., 2003). Their shells can act as relevant resources to ecosystems, contributing to several functions that can range from colonisable substrata to reservoirs of nutrients to the benthic compartment (Ilarri et al., 2012; Wenger et al., 2019). However, current studies on bivalve shells persistence and importance are few and in most cases have focused in the marine environment (Cadeé, 1999), being the freshwater ecosystems seldom investigated. Additionally, most of the studies regarding shells use were performed in laboratory, in which the shells were used as sensitive tools, to detect chemical contamination of the water due to their capacity to retain different heavy metals over different time periods (Bellotto and Miekeley, 2007; Nuñez et al., 2012; Karbasdehi et al., 2016), and to evaluated the influence of acidification on shell dissolution (Bednaršek et al., 2012; Bausch et al., 2018), whereas field studies are rare (but see Strayer and Malcom, 2007; Ilarri et al., 2015a). Overall, the findings of the present study suggest that the bivalve shell decays vary among species, shell size, water flow and season.

The four studied species have important differences in the shape and structure of their shells, which probably influenced the observed decay patterns. In the results of the treatments with shells available individually (i.e. in which the shells of each species had a similar size distribution) the interaction between the variables species and size suggested that the species with large shells such as A. anatina, U. delphinus and $P$. littoralis had a different pattern in the decays compared to $C$. fluminea. Size is a relevant variable to explain the decays, however for the treatments with shells available individually it was more difficult to detect the mass loss of $C$. fluminea. Shells of $C$. fluminea are much smaller than of the other three species, and consequently in absolute values loses much less mass (proportionally to its size) in comparison to the other three species. In the results of the treatments with shells available together (i.e. in which shells of $C$. fluminea and $U$. delphinus had different sizes), the interaction between species and size where able to detect differences in the two species. In this case in using an approach that included shells with different sizes, allowed us to detect mass loss variations for both species, including $C$. fluminea that present small shells, and consequently loss lower mass in a small period of time.

Few studies have evaluated the size as a variable for bivalve shells decays. Abdulghani (2014) observed that whole (with low surface area to volume ratio) shells of Crassostrea gigas, Ostrea lurida and Mytilus galloprovincialis had higher rates of shell mass loss than crushed shells (with high surface area to volume ratio). This result was different of what was expected and Abdulghani (2014) suggested that this was probably due to the higher proportion of organic matter in the whole shells compared to the crushed shells since high organic matter content contributes to high rates of microbial metabolism, increasing the dissolution of shell material (Waldbusser et al., 2011). In the present study we did not measure the proportion of organic matter of the shells, and we cannot exclude the possibility that this could have influenced our results. Ilarri et al. (2015a) tested the effective contribution of the size of the shells to the decays using the same four species and observed a small influence, of only $25 \%$ and $18 \%$ for the aquatic and terrestrial habitats, respectively. Furthermore, Strayer and Malcom (2007) also observed differences in the decay rates across species related to the size of the shell of four different freshwater bivalve species, including $C$. fluminea. Overall, in the present study size showed to be a relevant variable, especially for the treatments with shells of different size classes (small, medium and large). As expected, smaller shells that have a higher surface area to volume ratio, which accelerate the thermodynamic dissolution of shells (Waldbusser et al., 2011), had the highest percentage of decay in both species (C. fluminea and U. delphinus). However, when comparing the decays between both species for all size classes, the larger and thin shelled species $U$. delphinus showed the highest decays. These decays varied in the order of 1.50 (lentic habitat) to 1.81 (lotic habitat) times higher than of the small and thick $C$. fluminea shells. In this case more than the size of the species, the robustness of the shells showed to be more relevant to the decays, with the species $C$. fluminea showing the lowest values compared to U. delphinus. Indeed, shell thickness can influence the robustness of a shell and previous studies have already shown the importance of shell robustness to the shell decay process (Pearce, 2008; Strayer and Malcom, 2007).

The results also showed that the decays were more evident in the lotic than in the lentic habitats. According to Strayer and Malcom (2007), the rate of shell loss can be influenced by the current velocity. Mincy (2012) also found a positive relationship between current 
A

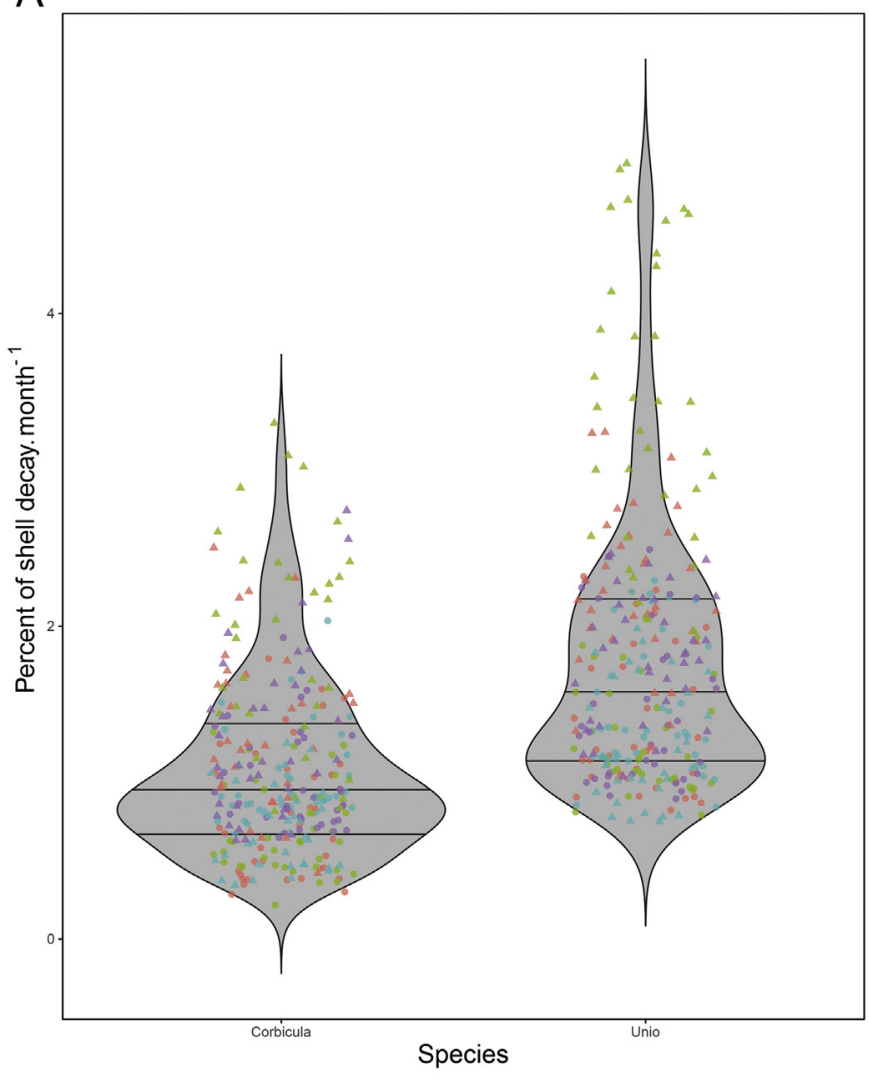

Season - Spring - summer - Autumn - Winter River flow - Lentic $\Delta$ Lotic

B

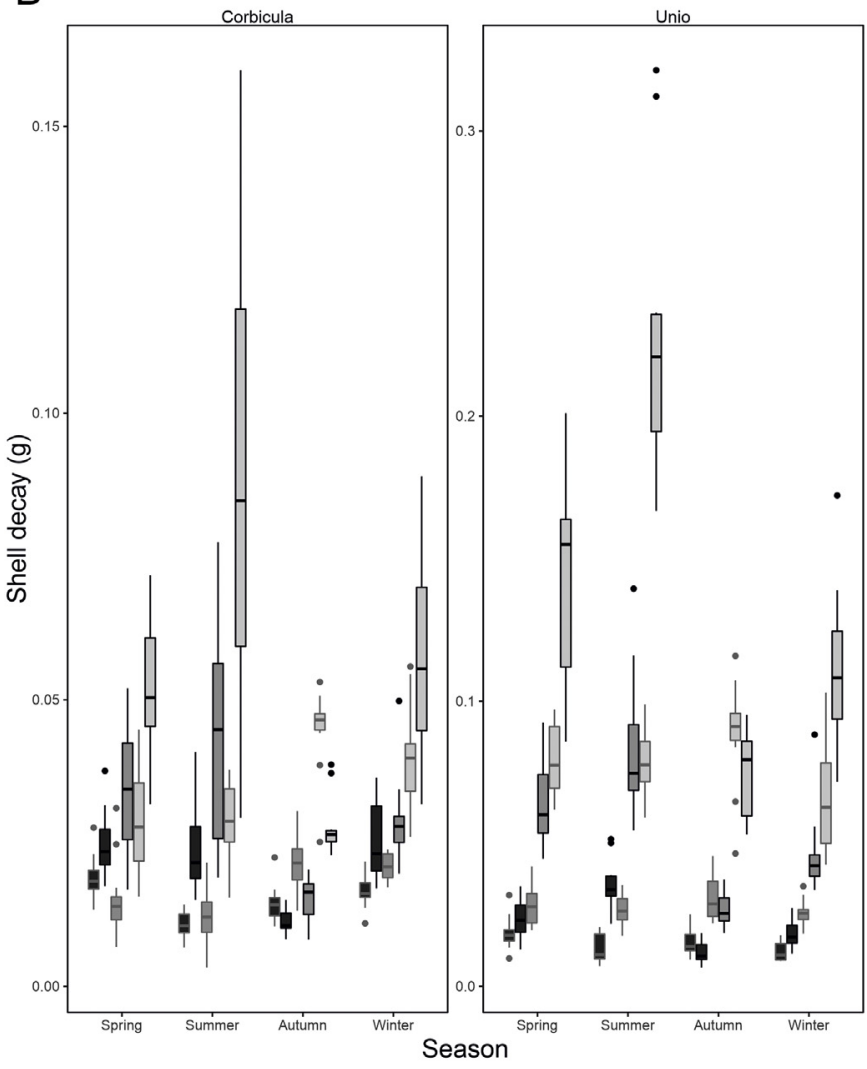

Size velocity (seven different velocity flows were selected) and shell decays of Villosa iris and C. fluminea. The lotic site (L1) is more heterogeneous in terms of flow than the lentic site (L2), and this probably contributed to the different decays observed. A higher decay rate was observed for all species in the lotic than in lentic zones. The only exception to this pattern was during the autumn, when the net bags made available in the lotic site were naturally covered by terrestrial plant leaves, which possibly contributed to the slower shell decay of the four species, suggesting that the leaves had a burial effect contributing to the shells preservation. This effect was stronger in the thin shelled species (A. anatina and $U$. delphinus) that during autumn had lower mass loss in the lotic conditions compared to the other seasons, and also to the other species that have thicker shells (C. fluminea and P. littoralis).

The decays showed also to be distinct seasonally, as expected. Lower decay rates were expected in summer due to the lower current velocity in this period of the year. Overall, summer was the season with the lowest decays only for some treatments available in the lentic site (L2). In the lotic site (L1) this result was different of the expected, with the lowest decays observed always during autumn. This was also probably associated to the buried effect provided by the net bags that were naturally covered by leaves.

Beyond the factors that were previously described, shell decay rates can be influenced by several other extrinsic (water chemistry) and intrinsic (mineralogy, chemical composition and organic matter) factors (Strayer and Malcom, 2007). In estuarine areas, low salinity values and high productivity can contribute to different decays, with the dissolution rates being a result of the combination of physical, biological, and chemical processes (Waldbusser et al., 2011). Available data of the area (see Sousa et al., 2007; Ferreira-Rodríguez et al., 2017) suggest that the water in the study sites has low $\mathrm{Ca}^{2}$ content. In fact, Ferreira-Rodríguez et al. (2017) observed low $\mathrm{Ca}^{2}$ content in the soft bodies of $C$. fluminea collected in the Minho River, which corroborates with the fact that $\mathrm{Ca}^{2}$ concentrations in Minho River is low. According to Strayer and Malcom (2007) in under-saturated waters the shell decays are controlled mostly by the chemical dissolution. This probably also occurs in the Minho River. Bivalve shells may contain different proportions of inorganic and organic matter, and the fraction of inorganic and organic matter can influence the decay rates; however, there is a lack of studies regarding this topic, especially concerning the organic matter content (Abdulghani, 2014). Therefore, more research is needed to investigate the very wide range of the bivalve shell decays, including information on the inorganic and organic content of the bivalve shells.

Shells can have many positive influences from an ecological perspective. They provide suitable substrate for attachment and refuge for many species, reduction of the physical and/or physiological stress, and also as reservoirs of nutrients to the benthic compartment (Gutiérrez et al., 2003; Ilarri et al., 2012, 2015b, 2018; Wenger et al., 2019). In fact, in previous studies performed in the Minho River it was possible to observe that the shells of the selected species attracted a relevant and similar macrozoobenthic community (Ilarri et al., 2015b). As showed by the results of the present study, shell decays can be context dependent being important the study of the factors that influence their availability in the ecosystems. The shells selected for this study comprise shells of native bivalve species (A. anatina, P. litorallis, U. delphinus), and one invasive species (C. fluminea). The native bivalve species in the study area (and other systems) are disappearing. Actually in Minho River they represent about $1 \%$ of the empty shells available (Ilarri et al., 2015a), suggesting that the ecological role provided by their shells are expected to reduce in the future. On the other hand, shells of the

Fig. 3. a. Mean percentage of shell decay of Corbicula fluminea (i.e. Corbicula) and Unio delphinus (i.e. Unio) per season (spring, summer, autumn and winter) and water flow (lentic and lotic), when available together in different size. b. Mean ( \pm sd) shell decay (g) per month of the species Corbicula fluminea (i.e. Corbicula) and Unio delphinus (i.e. Unio) per season (spring, summer, autumn and winter), water flow (lentic and lotic) and size class variation (small, medium and large). 
Table 4

Generalized linear model outputs made with the treatments containing three shells of different size of the species $C$. fluminea and $U$. delphinus (quasipoisson model). Significant results are in italic.

\begin{tabular}{llllll}
\hline $\begin{array}{l}\text { Response } \\
\text { variable }\end{array}$ & Parameter & Estimate & SE & t-Value & p-Value \\
\hline Decay & Intercept & & & & \\
& Size & -5.55 & 0.12 & -45.48 & $<0.001$ \\
& Species (Unio) & 0.062 & 0.0035 & 17.69 & $<0.001$ \\
& River flow (Lotic) & 0.20 & 0.14 & 1.42 & 0.16 \\
& Season (Spring) & -0.13 & 0.07 & -1.79 & 0.07 \\
& Season (Summer) & -0.17 & 0.061 & -2.75 & $<0.01$ \\
& Season (Winter) & -0.24 & 0.063 & -3.74 & $<0.001$ \\
& Size vs species (Unio) & -0.0095 & 0.062 & 1.53 & 0.13 \\
& Species (Unio) vs river flow & -0.019 & 0.0037 & -5.10 & $<0.001$ \\
& (Lotic) & 0.12 & 0.059 & 2.01 & $<0.05$ \\
& River flow (Lotic) vs season \\
(Spring) & 0.61 & 0.085 & 7.12 & $<0.001$ \\
& $\begin{array}{lllll}\text { River flow (Lotic) vs season } \\
\text { (Summer) }\end{array}$ & 1.08 & 0.084 & 12.94 & $<0.001$ \\
& $\begin{array}{l}\text { River flow (Lotic) vs season } \\
\text { (Winter) }\end{array}$ & 0.37 & 0.086 & 4.31 & $<0.001$ \\
& & & & & \\
\hline
\end{tabular}

invasive bivalve species, such as $C$. fluminea that nowadays dominates the infauna of the lower Minho River, are expected to increase, dominate and persist in this, and in other invaded systems, providing a higher contribution as ecosystem engineer to other organisms.

\section{Conclusion}

Overall, it was possible to conclude that the size of the shells showed to be a relevant variable to explain decays, with the smallest shells presenting the highest values. Also, for thick shelled species more than their size, their robustness showed to be a relevant feature, with the species with the thickest shells showing the lowest decays. The river flow showed also to be important, with higher values observed in the lotic compared to the lentic systems, the only exception was when in burial condition, such as when the shells were covered by leaves. The decays also varied seasonally, with the lower rates observed mainly during summer (for the lentic site), and autumn (for the lotic site). Ecologically, the results of the present study suggest that shells of the native species $A$. anatina and $U$. delphinus are expected to persist less and contribute less as ecosystem engineers, than shells of the native $P$. littoralis and the invasive $C$. fluminea species that are expected to prevail, especially in lentic habitats in which the decays showed to be up to 2.13 times lower than in the lotic habitats.

\section{Acknowledgments}

This study was supported by the FCT (Foundation for Science and Technology, Portugal) strategic fund UID/Multi/04423/2019.

\section{References}

Abdulghani, L., 2014. Examination of Bivalve Shell Degradation for Alkalinity Regeneration Purposes in Hood Canal, Washington. (Master thesis). The Evergreen State College.

Bausch, A.R., Gallego, M.A., Harianto, J., Thibodeau, P., Bednaršek, N., Havenhand, J.N., Klinger, T., 2018. Influence of bacteria on shell dissolution in dead gastropod larvae and adult Limacina helicina pteropods under ocean acidification conditions. Mar. Biol. 165 (2), 2-9.

Bednaršek, N., Tarling G.A., Bakker, D.C.E., Fielding, F, Cohen, A, Kuzirian, A, Dan McCorkle, D., Lézé, B., Montagna, R., 2012. Description and quantification of pteropod shell dissolution: a sensitive bioindicator of ocean acidification. Glob. Chang. Biol. 18, 2378-2388.

Bellotto, V.R., Miekeley, N., 2007. Trace metals in mussels shells and corresponding soft tissue samples: a validation experiment for the use of Perna perna shells in pollution monitoring. Anal. Bioanal. Chem. 389, 769-776.

Bódis, E. Tóth, B., Szekeres, J.. Borza, P., Sousa, R., 2014. Empty native and invasive bivalve shells as benthic habitat modifiers in a large river. Limnologica 49, 1-9.

Cadeé, G.C., 1999. Bioerosion of shells by terrestrial gastropods. Lethaia 32, 253-260.
Erwin, D., 2008. Macroevolution of ecosystem engineering, niche construction and diversity. Trends Ecol. Evol. 23, 304-310.

Ferreira-Rodríguez, N., Fernández, I., Varandas, S., Cortes, R., Cancela, M.L., Pardo, I., 2017. Sci. Total Environ. 580, 1363-1370.

Gutiérrez, J.L., Jones, C.G., Strayer, D.L., Iribarne, O.O., 2003. Mollusks as ecosystem engineers: the role of shell production in aquatic habitats. Oikos 101, 79-90.

Gutiérrez, J.L., Jones, C.G., Sousa, R., 2014. Toward an integrated ecosystem perspective of invasive species impacts. Acta Oecol. 54, 131-138.

Ilarri, M.I., Freitas, F., Costa-dias, S., Antunes, C., Guilhermino, L., 2012. Associated macrozoobenthos with the invasive Asian clam Corbicula fluminea. J. Sea Res. 72 113-120.

Ilarri, M., Souza, A., Sousa, R., 2015a. Contrasting decay rates of freshwater bivalves' shells: aquatic versus terrestrial habitats. Limnologica 51, 8-14.

Ilarri, M.I., Souza, A.T., Modesto, V., Guilhermino, L., Sousa, R., 2015b. Differences in the macrozoobenthic fauna colonising empty bivalve shells before and after invasion by Corbicula fluminea. Mar. Freshw. Res. 66, 549-558.

Ilarri, M.I., Amorim, L., Souza, A.T., Sousa, R., 2018. Physical legacy of freshwater bivalves: effects of habitat complexity on the taxonomical and functional diversity of invertebrates. Sci. Total Environ. 634, 1398-1405.

Jones, C.G., Lawton, J.H., Shachak, M., 1994. Organisms as ecosystem engineers. Oikos 69, 373-386.

Jones, C.G., Lawton, J.H., Shachak, M., 1997. Positive and negative effects of organisms as physical ecosystem engineers. Ecology 78, 1946-1957.

Karbasdehi, V., N., Dobaradaran, S., Nabipour, I., Ostovar, A., Vazirizadeh, A., Ravanipour, M., Nazmara, S., Keshtkar, M., Mirahmadi, R., 2016. J. Environ. Health Sci. Eng. 14: $16,1-12$.

Lenth, R.V., 2016. Least-squares means: the R package lsmeans. J. Stat. Softw. 69 (1), 1-33. Lutaenko, K.A., 2012. Transportation of bivalve shells with attached algae in Ussuriysky Bay (Sea of Japan). Bull. Russ. Far East. Malocol. Soc. 15/16, 154-164.

Lutaenko, K.A., Levenets, I.R., 2015. Observations on seaweed attachment to bivalve shells in Peter the Great Bay (East Sea) and their taphonomic implications. Korean J. Malocol. 31 (3), 221-232

Marshall, D., Aminuddin, A., Mustapha, N., Ting Teck Wah, D., De Silva, L., 2018. Gastropod Shell Dissolution as a Tool for Biomonitoring Marine Acidification, With Reference to Coastal Geochemical Discharge (Preprints, 2018030022).

Mincy, G.A., 2012. Mussel Survivorship, Growth Rate and Shell Decay Rate in the New River Basin of Tennessee: An Experimental Approach Using Corbicula fluminea. Master thesis. University of Tennessee.

Novais, A., Souza, A., Ilarri, M., Pascoal, C., Sousa, R., 2015. Facilitation in the low intertidal: effects of an invasive species on the structure of an estuarine macrozoobenthic assemblage. Mar. Ecol. Prog. Ser. 522, 157-167.

Novais, A., Souza, A., Ilarri, M.I., Pascoal, C., Sousa, R., 2016. Effects of the invasive clam Corbicula fluminea (Müller, 1774) on an estuarine microbial community. Sci. Total Environ. 566-567, 1168-1175.

Novais, A., Batista, D., Cássio, F., Pascoal, C., Sousa, R., 2017. Effects of invasive clam (Corbicula fluminea) die-offs on the structure and functioning of freshwater ecosystems. Freshw. Biol. 62, 1908-1916.

Nuñez, J.D., Laitano, M.V., Cledón, M., 2012. An intertidal limpet species as a bioindicator: pollution effects reflected by shell characteristics. Ecol. Indic. 14, 178-183.

Palacios, R., Armstrong, D.A., Orensanz, J., 2000. Fate and legacy of an invasion: extinct and extant populations of the soft-shell clam (Mya arenaria) in Grays Harbor (Washington). Aquat. Conserv. 10, 279-303.

Pearce, T.A., 2008. When a snail dies in the forest, how long will the shell persist? Effect of dissolution and micro-bioerosion. Am. Malacol. Bull. 26, 111-117.

R Development Core Team, 2014. R: a language and environment for statistical computing. The R Foundation for Statistical Computing, Vienna, Austria Available online at http://www.R-project.org/ (ISBN 3-900051-07-0).

Schmidlin, S., Schmera, D., Baur, B., 2012. Alien molluscs affect the composition and diversity of native macroinvertebrate in a sandy flat of Lake Neuchâtel, Switzerland. Hydrobiologia 679, 233-249.

Sousa, R., Guilhermino, L., Antunes, C., 2005. Molluscan fauna in the freshwater tidal area of the River Minho estuary, NW of Iberian Peninsula. Ann. Limnol. Int. J. Limnol. 41, 141-147.

Sousa, R., Antunes, C., Guilhermino, L., 2007. Species composition and monthly variation of the molluscan fauna in the freshwater subtidal area of the River Minho estuary. Estuar. Coast. Shelf Sci. 75, 90-100.

Sousa, R., Rufino, M., Gaspar, M., Antunes, C., Guilhermino, L., 2008. Abiotic impacts on spatial and temporal distribution of Corbicula fluminea (Müller, 1774) in the river Minho estuary, Portugal. Aquat. Conserv. 18, 98-110.

Strayer, D.L., Malcom, H.M., 2007. Shell decay rates of native and alien fresh-water bivalves and implications for habitat engineering. Freshw. Biol. 52, 1611-1617.

Vaughn, C.C., Hoellein, T.J., 2018. Bivalve impacts in freshwater and marine ecosystems. Annu. Rev. Ecol. Evol. Syst. 49, 183-208.

Venables, W.N., Ripley, B.D., 2002. Modern Applied Statistics With S. Fourth edition. Springer, New York

Waldbusser, G.G., Steenson, R.A., Green, M.A., 2011. Oyster shell dissolution rates in estuarine waters: effects of pH and shell legacy. J. Shellfish Res. 30, 659-669.

Wenger, S.J., Subalusky, A.L., Freeman, M.C., 2019. The missing dead: the lost role of animal remains in nutrient cycling in North American Rivers. Mar. Microb. Food Webs $18(1-6)$

Wright, J.P., Jones, C.G., 2006. The concept of organisms as ecosystem engineers ten years on: progress, limitations, and challenges. BioScience 56 (3), 203-209.

Zuur, A.F., Ieno, E.N., Walker, N.J., Saveliev, A.A., Smith, G.M., 2009. Mixed Effects Models and Extensions in Ecology With R. Springer, Berlin. 